\title{
LEFT VENTRICULAR MYOCARDIAL NON COMPACTION IN A CHILD AFFECTED BY CRI DU CHAT SYNDROME
}

\section{MARCELLO MARCI'1}

${ }^{1}$ Azienda Ospedaliera Ospedali Riuniti Villa Sofia Cervello

March 21, 2021

\begin{abstract}
The following is a case report of an infant born with cri du chat syndrome that has evidence of left ventricular non compaction . Cri du chat syndrome is a rare association of growth retardation, intellectual severe disability, hypertelorism and typical catlike cry, typically combined to congenital heart defect, the occurrence of myocardial non compaction among the associated cardiac anomalies has not been reported so far.
\end{abstract}

\section{Hosted file}

myocardial non compaction BIBLIORIDOTTA.pdf available at https://authorea.com/users/403042/ articles/514710-left-ventricular-myocardial-non-compaction-in-a-child-affected-by-cridu-chat-syndrome

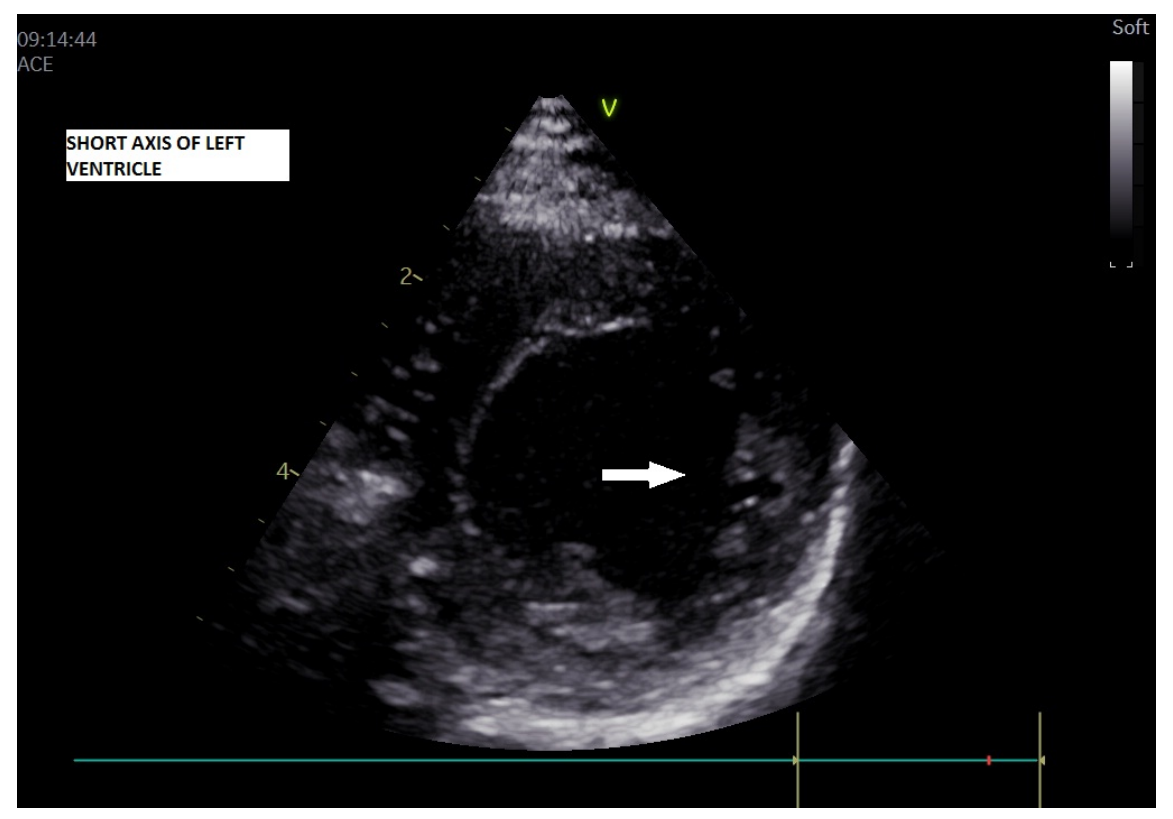




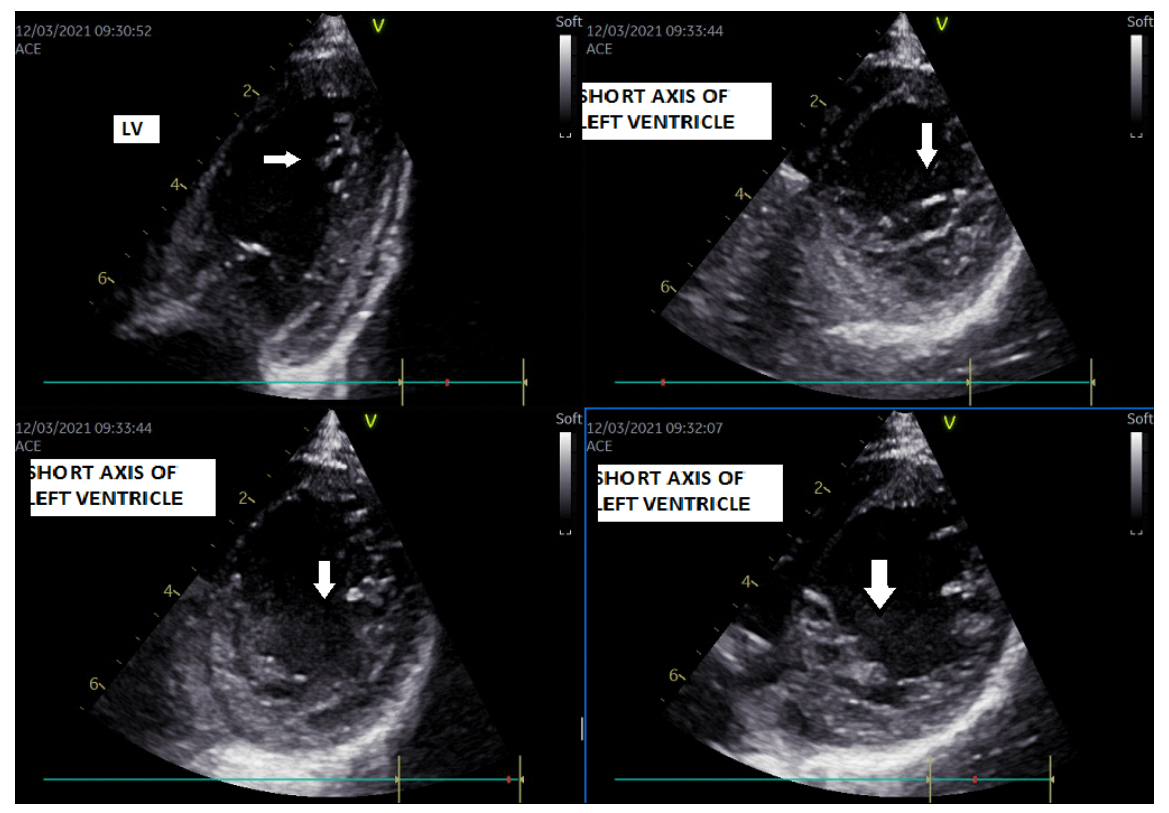

